\title{
Controllable immobilization of polyacrylamide onto glass slide: synthesis and characterization
}

\author{
Linghan Xiao $\cdot$ Xin Zheng • Tianyi Zhao $\cdot$ Liying Sun • \\ Fengqi Liu • Ge Gao • Alideertu Dong
}

Received: 7 January 2013 /Revised: 1 May 2013 / Accepted: 4 May 2013 / Published online: 19 May 2013

(C) The Author(s) 2013. This article is published with open access at Springerlink.com

\begin{abstract}
A novel route was introduced to synthesize dense polyacrylamide (PAM) onto the glass slide surface. To investigate the surface chemistry of the PAM on the glass slides, X-ray photoelectron spectroscopy (XPS) was utilized to obtain detailed chemical state information on the PAM layer constituents. The XPS peak data were consistent with the presented model of the PAM on the glass slide surface. Scanning electron microscopy and atomic force microscope data indicated the presence of PAM on the glass slides, which consist of nodules. The results showed that PAM was successfully immobilized onto glass slides with a twotier structure under aqueous condition and a monolayer structure under anhydrous condition. Compared with those under aqueous condition, the controllability of the molecular layer on glass slides and the reproducibility under anhydrous condition were much better, which makes anhydrous condition an advisable condition for the study of the reaction mechanisms of glass slides modified by PAM.
\end{abstract}

Keywords Glass slide · Polyacrylamide - Surface analysis · XPS · SEM · AFM

\section{Introduction}

Glass slides have a wide range of applications in life scientific research. However, the glass slides could not fully meet experimental requirements, for silicon-oxygen bond on the

L. Xiao $\cdot$ X. Zheng $\cdot$ T. Zhao $\cdot$ L. Sun $\cdot$ F. Liu $\cdot$ G. Gao $(\bowtie)$

College of Chemistry and MacDiarmid Laboratory, Jilin

University, Changchun 130021, People's Republic of China

e-mail: gaoge8888@gmail.com

\section{A. Dong $(\square)$}

College of Chemistry and Chemical Engineering, Inner Mongolia

University, Hohhot 010021, People's Republic of China

e-mail: dongali@yahoo.cn glass slides without surface activation is stable and lacks sufficient chemical activity. Therefore, in recent years, glass slide surface modification research is gradually arousing researcher's interest. Surface modification with small molecules alone or in combination with short molecular chains is the main approach in a heterogeneous immunoassay. Compared with small molecules, functional polymers offer many advantages for surface activation. First, polymers carry abundant functional groups, which can be used for covalent and high-density probe immobilization. Second, it is easy to control surface properties by selecting suitable polymers. Moreover, the long chain of polymers can work as a spacer between a probe and a substrate, which helps to preserve native sample conformation, so as to reduce steric hindrance and to improve accessibility of probes for analysis.

The most popular way to prepare reactive coatings on glass surfaces is based on the formation of self-assembled monolayers of alkylchlorosilanes or alkylalkoxysilanes, which bear a variety of active groups like amine, thiol, and epoxy [1]. The silanization method is relatively inexpensive and easy to prepare and handle, but its low loading capacity and serious nonspecific adsorption restrict its application in sensitive protein assays [2]. Randomly oriented $\mathrm{ZnO}$ nanorod-coated glass slides were constructed as a substrate to improve the performance of a protein microarray through high protein loading capacity and significant fluorescence amplification [3]. Clusterassembled $\mathrm{TiO}_{x}$ nanostructures [4], multiwalled carbon nanotubes [5], and 3-D silica nanopillar bundles [6] also have been developed to immobilize on glass slides. In addition, in situ grown polymer brushes can function as attractive alternatives to pre-synthesized polymers/copolymers because their thickness, roughness, and hydrophily can be easily controlled by adjusting monomer components and polymerization conditions. Furthermore, polymer brushes of poly[oligo(ethylene glycol)methacrylate] and poly(dimethylacrylamide- $\mathrm{Co}-\mathrm{N}, \mathrm{N}$ acryloyloxysuccinimide) were grafted on glass slides as supporting matrixes for chip-based immunoassays [7, 8]. 
Currently, with the development of biotechnology and materials science, amino-modified glass slides in immune biodetection $[9,10]$, polymer-coated materials [11], and so on show great potential applications.

Silane coupling agents are commonly used to activate surfaces for subsequent immobilization of biomolecules, but this method cannot meet the requirement of the number of surface amino. Therefore, a new route is introduced to synthesize dense amino polymers on the glass slide surface, and the different experimental conditions, including the effects of reaction temperature, reaction time, concentrations of acrylamide (AM) and the catalyst, may all provide different outcomes of polyacrylamide (PAM) quality in terms of surface morphology and thickness. The solvent of reaction is still a major factor to determine nodule density and surface morphology. Amino-modified glass slides could be characterized by Fourier transformation IR [12-14], X-ray photoelectron spectroscopy (XPS) [11, 15], scanning electron microscopy (SEM), atomic force microscope (AFM), and so on. These characteristics can tell the information about the number of amino, amino layer thickness, amino density, and bonding structure of the surface modification of glass slide. It is an excellent new example of applied surface science.

\section{Experimental}

\section{Materials}

AM was purchased from the Tianjin Huadong Chemical Reagent Plant. Thionyl chloride $\left(\mathrm{SOCl}_{2}\right)$ was obtained from the Tianjin Guangfu Fine Chemical Research Institute. Anhydrous ethanol, tetrahydrofuran (THF), cerous ammonium nitrate (CAN), hydrochloric acid $(\mathrm{HCl})$, and ammonium hydroxide (25 wt $\%$ ) were purchased from the Beijing Chemical Company. Ethylenediamine and hydrogen peroxide $\left(\mathrm{H}_{2} \mathrm{O}_{2}\right)$ were available from the Tianjin Chemical Reagent Plant and the Shanghai Chemical Reagent Plant, respectively. All reagents were in analytical grade and were used without any purification.

\section{Hydroxylation of glass slides}

For AFM, XPS, and SEM measurements, the glass slides were cut to a size of $1.0 \times 1.0 \mathrm{~cm}^{2}$. All glass slides were sonicated for $30 \mathrm{~min}$ in soapy water made from deionized water and glass cleaner and for another $30 \mathrm{~min}$ in deionized water again. Glass slides were then treated in the following steps: washing with a base solution consisting of 1:1:5 $(\mathrm{v} / \mathrm{v})$ of $30 \% \mathrm{H}_{2} \mathrm{O}_{2}, 28 \sim 30 \% \mathrm{NH}_{3} \cdot \mathrm{H}_{2} \mathrm{O}$, and distilled water at $80{ }^{\circ} \mathrm{C}$ for $5 \mathrm{~min}$; rinsing with $10 \mathrm{~mL}$ of $30 \% \mathrm{H}_{2} \mathrm{O}_{2}$; washing with an acid solution consisting of 1:1:5 $(\mathrm{v} / \mathrm{v})$ of $30 \%$
$\mathrm{H}_{2} \mathrm{O}_{2}$-conc. $\mathrm{HCl}$-distilled water at $80{ }^{\circ} \mathrm{C}$ for $5 \mathrm{~min}$; and rinsing again with $10 \mathrm{~mL}$ of $30 \% \mathrm{H}_{2} \mathrm{O}_{2}$. The glass slides were then rinsed with methanol, dichloromethane, and diethyl ether, sequentially, and at last, were dried in an oven overnight at $150{ }^{\circ} \mathrm{C}$.

\section{Ethylenediamine modification of glass slides}

Dried hydroxyl-functionalized glass slides were reacted with excess neat $\mathrm{SOCl}_{2}(50 \mathrm{~mL})$ at $70{ }^{\circ} \mathrm{C}$ for $24 \mathrm{~h}$. The residual $\mathrm{SOCl}_{2}$ was removed by distillation under reduced pressure at $30{ }^{\circ} \mathrm{C}$. The glass slides were washed three times with anhydrous THF and dried in a vacuum at room temperature for $5 \mathrm{~h}$. Then, the glass slides were reacted with $50 \mathrm{~mL}$ of ethylenediamine at $100{ }^{\circ} \mathrm{C}$ for 2 days. After cooling to room temperature, the glass slides were washed with anhydrous ethanol for five times to remove excess ethylenediamine. Finally, the ethylenediamine-modified glass slides were dried at room temperature overnight in a vacuum.

\section{Immobilization of polyacrylamide onto glass slides}

For the surface-initiated graft polymerization, dried ethylenediamine-modified glass slides were put into $100 \mathrm{~mL}$ of deionized water for $30 \mathrm{~min}$. Then, $10 \mathrm{~mL}$ of $1 \mathrm{M}$ aqueous solution of acrylamide was added. After deaeration of the system by bubbling nitrogen, $0.5 \mathrm{~mL}$ of $0.2 \mathrm{M}$ solution of CAN in $1 \mathrm{M}$ nitric acid was slowly added to initiate graft copolymerization. Graczyk and Hornof [16] reported that stirring speed was an important variable in determining percent conversion of monomer to polymer during graft polymerization. Therefore, the reaction mixture was stirred at a constant rate to avoid the effect of stirring on the rate of graft copolymerization. The polymerization was conducted at $30{ }^{\circ} \mathrm{C}$ under dry nitrogen for some times. The PAM grafting glass slides were washed with distilled
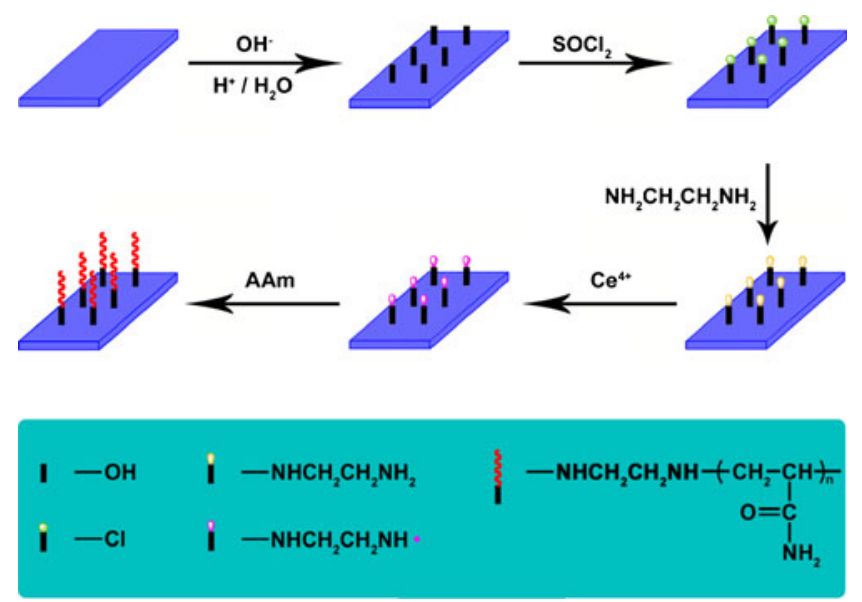

Fig. 1 Outlines of the surface initiated redox polymerization of acrylamide on glass slide 
Fig. $2 \mathrm{Cl} 2 \mathrm{p}$ XPS narrow-scan spectra of the glass slide treated with $\mathrm{SOCl}_{2}$ a under aqueous condition and $\mathbf{b}$ under anhydrous condition

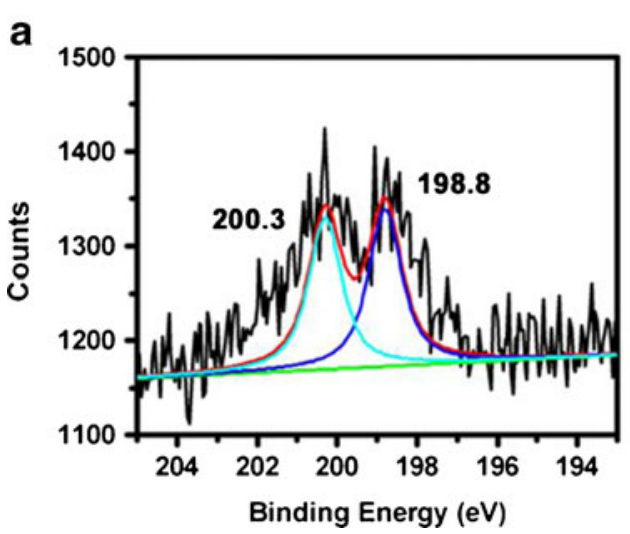

water and subsequently dried overnight in a vacuum. For comparison, anhydrous ethanol was chosen to replace the original deionized water to investigate the effect of water on a reaction system. The processes of treatment and polymerization of glass slides are shown in Fig. 1.

\section{Characterization}

SEM images were taken on the JEOL JSM-6701 F scanning electron microscope. XPS measurement was carried out on the PHI-5000CESCA system with $\mathrm{Mg} \mathrm{K}$ radiation $(\mathrm{hr}=$ 1,253.6 eV). The X-ray anode was run at $250 \mathrm{~W}$, and the high voltage was kept at $14.0 \mathrm{kV}$ with a detection angle at 540. All the binding energies were calibrated using the containment carbon (C $1 \mathrm{~s}=284.6 \mathrm{eV})$. AFM images were recorded using the Nanoscope IIIa multimode atomic force microscope.

\section{$X P S$}

XPS was used to determine the surface compositions of the glass slides. The samples were mounted onto a stainless steel sample holder and fixed in place with copper clips and stainless steel screws. The XPS system was equipped with an analyzer and a detector. The observed volume was given by a diameter of the photon beam at the sample surface about $10 \mathrm{~mm}^{2}$ and the information depth of the method used. Wide-survey and narrow scans of $\mathrm{C} 1 \mathrm{~s}, \mathrm{O}$ $1 \mathrm{~s}, \mathrm{~N} 1 \mathrm{~s}$, and $\mathrm{Cl} 2 \mathrm{p}$ were recorded at $20 \mathrm{eV}$ pass energy. b

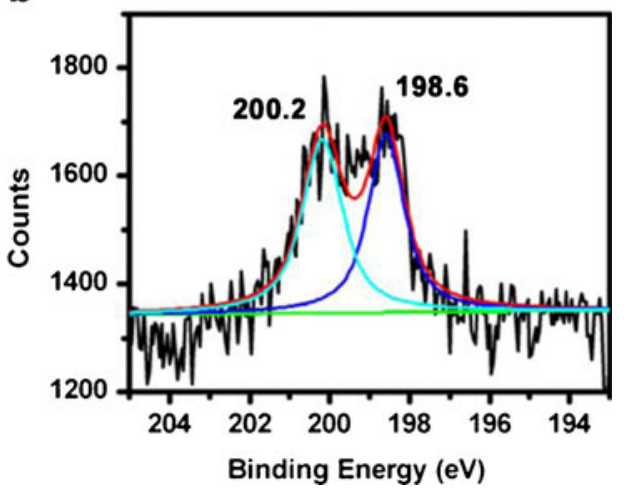

Atomic concentrations were determined while accounting for photoelectron cross-sections, asymmetry parameters, the inelastic mean free path, and experimentally determined transmission function of the energy analyzer. To avoid the expected ion beam-induced modification of atomic composition in the investigated volume, the sample surfaces were analyzed without sputter cleaning.

\section{SEM}

The field emission scanning electron microscopy images were obtained on the JEOL JSM-6701 F field emission scanning electron microscope. Because the conductivity of the samples was not sufficient for SEM, the samples were loaded on the surface of a copper substrate which was previously sputter coated with a homogeneous gold layer charge dissipation during the SEM imaging. SEM images were examined using the JEM-1200EX (JEOL, Japan) microscope. All experiments were conducted at room temperature.

\section{Results and discussion}

Elemental composition

The elemental surface composition of the glass slide under different conditions is shown in Fig. $2 \mathrm{a}, \mathrm{b}$.

Fig. 3 N 1 s XPS narrow-scan spectra of the nitrogenincorporated glass slide obtained from ethylenediamine a under aqueous condition and b under anhydrous condition a

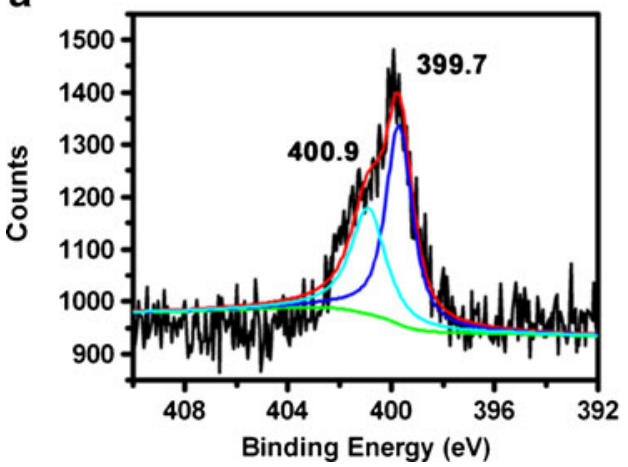

b

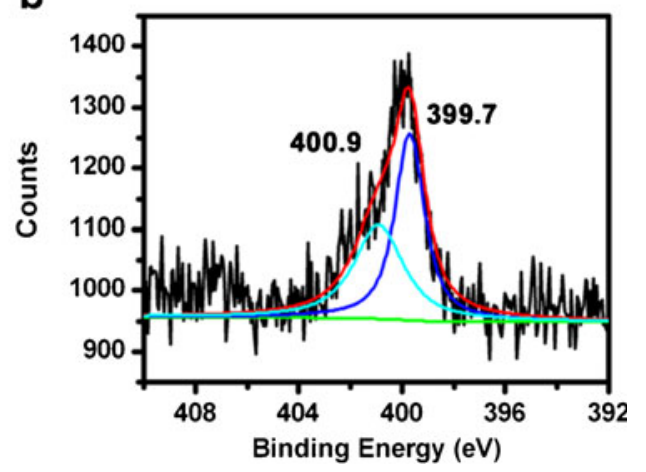


Fig. 4 N 1 s XPS narrow-scan spectra of the glass slide obtained from PAM a under aqueous condition and $\mathbf{b}$ under anhydrous condition

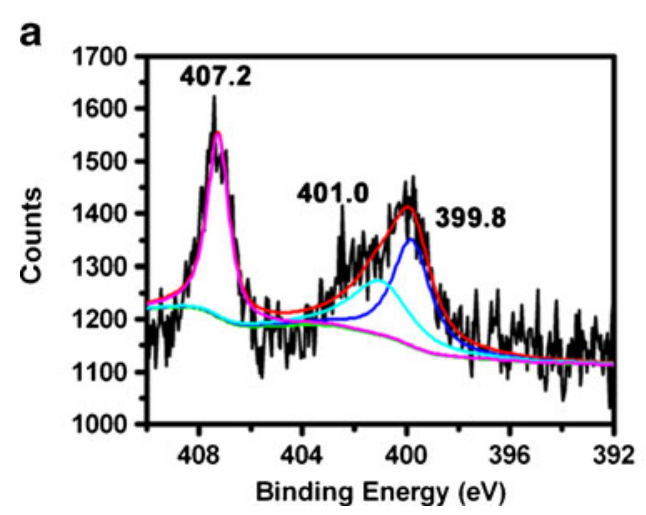

In Fig. 2a, there are two chemical states of chlorine represented by the peaks at 198.8 and $200.3 \mathrm{eV}$ for $\mathrm{Cl} 2 \mathrm{p}$, illustrating the successful introduction of the $\mathrm{Si}-\mathrm{Cl}$ bond [17]. In Fig. 2b, there are two chemical states of chlorine represented by the peaks at 198.6 and $200.2 \mathrm{eV}$ for $\mathrm{Cl} 2 \mathrm{p}$, illustrating the successful introduction of the $\mathrm{Si}-\mathrm{Cl}$ bond, too. As shown in Fig. 2a, b, the presence of $\mathrm{Si}-\mathrm{Cl}$ bond is firmly demonstrated by the appearance of polar chlorine $\mathrm{Cl}$ (2p) peaks in the high-resolution XPS spectra.

In Fig. 3a, b, the glass slide has two chemical states of nitrogen represented by the peak at $399.7 \mathrm{eV}$ for $\mathrm{H}-\mathrm{N}-\mathrm{H}$ bond and the second peak at $400.9 \mathrm{eV}$ for $\mathrm{Si}-\mathrm{N}$ bond [18-20]. The $-\mathrm{NH}_{2}$ groups probably interact with other silanol groups by hydrogen bonding, explaining the high binding energy values compared with the other examples from the literature data (399.7 vs. $399.3 \mathrm{eV}$ ) [21-23]. The $\mathrm{N}$ $1 \mathrm{~s}(400.9 \mathrm{eV})$ photoelectron peak confirms that nitrogen in the glass slide has different bonding states, possessing higher binding energy than that of $\mathrm{Si}-\mathrm{N}$ configuration (400.3 eV) [24]. This is also a little difference from the reported peak positions of silicon oxynitride [25]. In this case, the amine groups would be interacting with the surface silane groups withdrawing their protons [26] and causing the appearance of the peak due to protonic species at a higher binding energy. This suggests that the bond structure is $\mathrm{Si}-\mathrm{N}$ protonated. Two chemical states of the N $1 \mathrm{~s}$ spectrum for the glass slide accord with the predesigned experimental route.

\section{b}

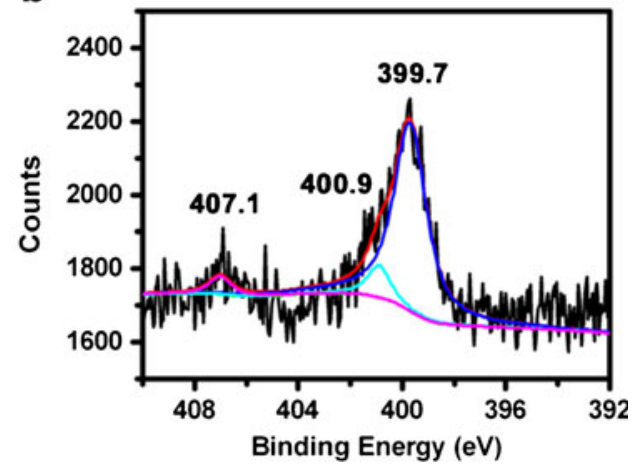

In Fig. 4a, b, the N $1 \mathrm{~s}$ spectra for the glass slide show an asymmetric and wide peak that is fitted by two components: one attributing to $-\mathrm{NH}_{2}(399.7 \mathrm{eV})$, and the other, to $\mathrm{Si}-\mathrm{N}$ $(401.0 \mathrm{eV})$ protonated. But the increase of the peak area of $\mathrm{N}$ (1 s) binding energy at $407.1 \mathrm{eV}$ [27] suggests that the bond structure is $-\mathrm{NO}_{2}$. In this case, some of the $-\mathrm{NH}_{2}$ groups were converted into $-\mathrm{NO}_{2}(407.2 \mathrm{eV})$ groups in aqueous condition as shown in Fig. 4a. A few $-\mathrm{NH}_{2}$ groups were converted into $-\mathrm{NO}_{2}(407.1 \mathrm{eV})$ groups under anhydrous condition as shown in Fig. 4b. Therefore, the numbers of $-\mathrm{NH}_{2}$ groups converted into $-\mathrm{NO}_{2}$ under aqueous condition are higher than those under anhydrous condition.

Glass slide surface morphology by SEM and AFM

A PAM-incorporated glass slide was imaged using SEM to investigate the surface morphology. A representative image is shown in Fig. 5a, which reveals a topology that is not completely smooth. Many interconnected nodules are apparent on the surface. There is also another polymer layer under the nodules. Hydrolysis reaction would probably happen under aqueous condition because of the water in the system, and it would generate irregular bimolecular layer on the surface of the glass slide. A similar granular surface pattern is shown in Fig. 5b, which indicates that the PAM was polymerized on the glass slide surface.

AFM images of the PAM-incorporated glass slide under aqueous condition are shown in Fig. 6a, b, respectively. It can

Fig. 5 A SEM image of a PAM-treated glass slide a under aqueous condition and $\mathbf{b}$ under anhydrous condition
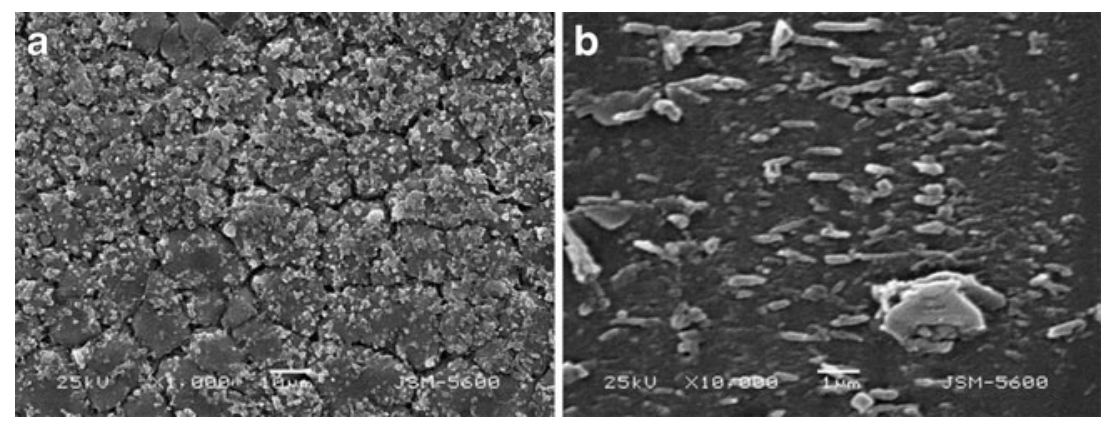
Fig. 6 AFM images of a PAMincorporated glass slide under aqueous condition
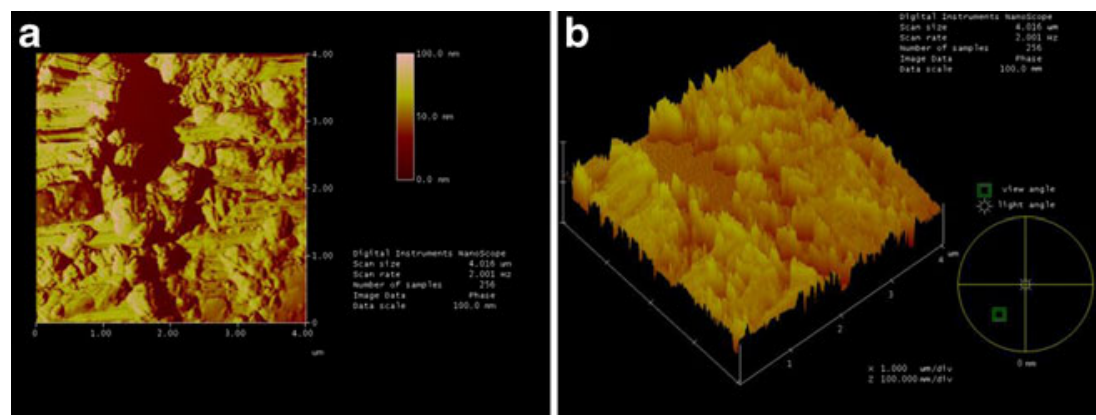

be seen from the scanned AFM images in Fig. 6a that the PAMincorporated glass slide under aqueous condition has more numerous bumps, pits, and nodules. In Fig. 6b, there is obviously a two-tier structure on the glass slide surface.

Figure $7 \mathrm{a}, \mathrm{b}$ shows AFM images of the PAMincorporated glass slide under anhydrous condition scanned at $10 \mu \mathrm{m}^{2}$ area. In Fig. 7a, the glass slide is relatively flat, but distinctive circular and oval particles are visible as islands. In Fig. 6b, the glass slide presents a relatively monolayer structure.

Glass slide polymerized more PAM nodules under aqueous condition than under anhydrous condition. The roughness is the significant evidence embodied the surface morphology. The PAM-incorporated glass slide under aqueous condition had a higher surface roughness of $150.46 \mathrm{~nm}$ than that under anhydrous condition of $130.72 \mathrm{~nm}$. It is known that this heterogeneity of glass slide can result in adsorption of small polar molecules, such as water, and this can promote an interaction of PAM by hydrolysis at these sites [28]. Therefore, it is probably prone to hydrolysis, resulting in an irregular two-tier structure on the glass slide surface due to the presence of water. It is difficult to control hydrolysis reaction in the system. As a result, the thickness of PAM molecular layer and the density of $-\mathrm{NH}_{2}$ on the surface are uncontrollable, and the reproducibility is not satisfactory. Compared with those under aqueous condition, the controllability of the molecular layer on glass slide and the reproducibility under anhydrous condition are much better, which makes anhydrous condition an advisable condition for the study of the reaction mechanisms of glass slide modified by PAM. AFM images confirmed a complete surface coverage of a similar topology which is concordant with what is observed in the SEM image.

As an aside, we have assigned the $\mathrm{N}(1 \mathrm{~s})$ peak at $399.7 \mathrm{eV}$ to the $\mathrm{NH}_{2}$ functionality, but it is worth noting that this peak can be deconvoluted into two different nitrogen species at 399.7 and $400.9 \mathrm{eV}$, which are a characteristic of an amine and a protonated amine group (ammonium), respectively $[29,30]$.

\section{Conclusions}

The presence of PAM on glass slide is firmly demonstrated by the presence of polar chlorine $\mathrm{Cl}(2 \mathrm{p})$ peaks and the change in the intensity of elemental N (1 s) peaks in the high-resolution XPS spectra. AFM and SEM provide detailed images of the surface morphology of the PAM layer. A major factor determining nodule density and surface morphology is the solvent of the reaction. PAM grown on glass slide under anhydrous condition resulted in the formation of continuous monolayer. The grown nodules can provide a continuous undulating sheet across glass slide. However, PAM grown on the glass slide surface under aqueous condition polymerized into a two-tier structure. Different applications of PAM layer have different requirements, according to its modification methods and reaction conditions to prepare for PAM layers with specific thickness, condensation degree, and amino group density. The application of PAM-modified glass slide will be greatly promoted in various fields, especially in biology and nanoscale material applications.
Fig. 7 AFM images of a PAMincorporated glass slide under anhydrous condition
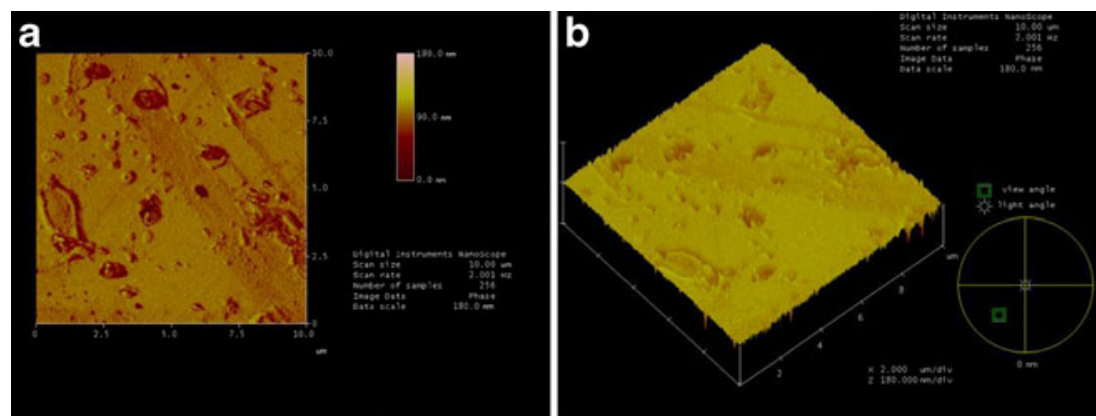
Acknowledgments We thank the National Natural Science Foundation of China (no. 50673033) and the National Natural Science Foundation of Jilin Province (no. 201115011) for their financial support.

Open Access This article is distributed under the terms of the Creative Commons Attribution License which permits any use, distribution, and reproduction in any medium, provided the original author(s) and the source are credited.

\section{References}

1. Kusnezow W, Jacob A, Walijew A, Diehl F, Hoheisel JD (2003) Antibody microarrays: an evaluation of production parameters. Proteomics 3(3):254-264

2. Afanassiev VHV, Wolfl S (2000) Preparation of DNA and protein micro arrays on glass slides coated with an agarose film. Nucleic Acids Res 28(12):e66

3. Hu WH, Liu YS, Zhu ZH, Yang HB, Li CM (2010) Randomly oriented $\mathrm{ZnO}$ nanorods as advanced substrate for highperformance protein microarrays. ACS Appl Mater Interfaces 2(6):1569-1572

4. Carbone R, De Marni M, Zanardi A, Vinati S, Barborini E, Fornasari L, Milani P (2009) Characterization of clusterassembled nanostructured titanium oxide coatings as substrates for protein arrays. Anal Biochem 394(1):7-12

5. Hu WH, Lu ZS, Liu YS, Li CM (2010) In situ surface plasmon resonance investigation of the assembly process of multiwalled carbon nanotubes on an alkanethiol self-assembled monolayer for efficient protein immobilization and detection. Langmuir 26(11):8386-8391

6. Kim SY, Yu J, Son SJ, Min J (2010) Signal enhancement in a protein chip array using a 3-D nanosurface. Ultramicroscopy 110(6):659-665

7. Hucknall A, Kim D-H, Rangarajan S, Hill RT, Reichert WM, Chilkoti A (2009) Simple fabrication of antibody microarrays on nonfouling polymer brushes with femtomolar sensitivity for protein analytes in serum and blood. Adv Mater 21(19):1968-1971

8. Cretich M, Di Carlo G, Giudici C, Pokoj S, Lauer I, Scheurer S, Chiari M (2009) Detection of allergen specific immunoglobulins by microarrays coupled to microfluidics. Proteomics 9(8):2098-2107

9. Yang HH, Qu HY, Lin P (2003) Nanometer fluorescent hybrid silica particle as ultrasensitive and photostable biological labels. Analyst 128(5):462-466

10. Jal PK, Patel S, Mishra BK (2004) Chemical modification of silica surface by immobilization of functional groups for extractive concentration of metal ions. Talanta 62(5):1005-1028

11. Perruchot C, Chehimi MM, Delamar M (1998) Use of aminosilane coupling agent in the synthesis of conducting, hybrid polypyrrolesilica gel particles. Surf Interface Anal 26(9):689-698

12. Satu E, Iiskola EI, Niinisto L (2003) Gas-phase deposition of aminopropylalkoxysilanes on porous silica. Langmuir 19(8):34613471

13. Shimizu I, Okabayashi H, Taga K (1997) Raman-scattering study of the interaction of 3-aminopropyltriethoxy silane on silica-geltime-dependent conformational change of aminopropylsilyl segments. Vib Spectrosc 14(1):125-132

14. Shimizu I, Okabayashi H, Taga K (1997) Diffuse-reflectance infrared Fourier-transform spectral study of the thermal and adsorbed-water effects of a 3-aminopropyltriethoxysilane layer modified onto the surface of silica-gel. Vib Spectrosc 14(1):113-123

15. Garbassi F, Balducci L, Chiurlo P (1995) A study of surface modification of silica using XPS, DRIFT and NMR. Appl Surf Sci 84(2):145-151

16. Graczyk T, Hornof V (1983) Effect of stirring on cellulose graft copolymerization. J Appl Polym Sci 28(4):1371-1378

17. Ishibashi K, Sakuraba M, Murota J, Inokuchi Y, Kunii Y, Kurokawa H (2006) A Study on B atomic layer formation for Bdoped $\mathrm{Si}_{1}-{ }_{x} \mathrm{Ge}_{x}(100)$ epitaxial growth using Ultraclean LPCVD System, ECS. Trans 3(7):861-866

18. Robertson J (1981) The electronic properties of silicon nitride. Philos Mag B 44(2):215-237

19. Robertson J (1983) Defect and impurity states in silicon nitride. J Appl Phys 54(8):4490-4494

20. Karcher R, Ley L, Johnson RL (1984) Electronic structure of hydrogenated and unhydrogenated amorphous $\operatorname{SiN}_{x}(0 \leq x \leq 1.6)$ : a photoemission study. Phys Rev B 30(4):1896-1910

21. Harder P, Bierbaum K, Woell C, Grunz M (1997) Induced orientational order in long alkyl chain aminosilane molecules by preadsorbed octadecyltrichlorosilane on hydroxylated $\mathrm{Si}(100)$. Langmuir 13(3):445-454

22. Bierbaum K, Kinzler M, Woell C, Grunze M, Häahner G, Heid S, Effenberger F (1995) A near-edge X-ray-absorption fine structure spectroscopy and X-ray photoelectron-spectroscopy study of the film properties of self-assembled monolayers of organosilanes on oxidized $\mathrm{Si}(100)$. Langmuir 11(2):512-518

23. Wagner CD, Riggs WM, Davis LE, Moulder JF, Muilenberg GE (1979) Handbook of X-ray photoelectron spectroscopy. PerkinElmer Corporation, Physical Electronics Division, Eden Prairie, Minn. 55344

24. Wan GJ, Yang P, Fu RKY, Yao ZQ, Huang N, Chu PK (2005) Improvement of nitrogen retained dose using ammonia as a precursor in nitrogen plasma immersion ion implantation of silicon. Vac Sci Technol A 23(5):1346-1349

25. Dasgupta A, Takoudis CG (2003) Two-step processes for bimodal $\mathrm{N}$ concentration profiles in ultra-thin silicon oxynitrides. Thin Solid Films 436(2): 162-167

26. Horr TJ, Arora PS (1997) Determination of the acid-base properties for 3-amino, 3-chloro and 3-mercaptopropyltrimethoxysilane coatings on silica surfaces by XPS. Colloids Surf, A Physicochem Eng Asp 126(2):113-121

27. Mills P, Sullivan JL (1983) A study of the core level electrons in iron and its three oxides by means of X-ray photoelectron spectroscopy. J Phys D 16(5):723-732

28. Bakaev VA, Bakaeva TI, Pantano CG (2002) A study of glass surface heterogeneity and silylation by inverse gas chromatography. J Phys Chem B 106(47):12231-12238

29. Eck W, Stadler V, Geyer W, Zharnikov M, Gölzhäuser A, Grunze M (2000) Generation of surface amino groups on aromatic self-assembled monolayers by low energy electron beams: a first step towards chemical lithography. Adv Mater 12(11):805-808

30. Bierbaum K, Kinzler M, Wöll C, Grunze M (1995) A near edge X-ray absorption fine structure spectroscopy and X-ray photoelectron spectroscopy study of the film properties of self-assembled monolayers of organosilanes on oxidized Si(100). Langmuir 11(2):512-518 